\title{
Burkina Faso: Community education program scaled-up in Burkina
} Faso

Frontiers in Reproductive Health

Follow this and additional works at: https://knowledgecommons.popcouncil.org/departments_sbsr-rh How does access to this work benefit you? Let us know!

\section{Recommended Citation}

"Burkina Faso: Community education program scaled-up in Burkina Faso," FRONTIERS OR Summary. Washington, DC: Population Council, 2005. 
Burkina Faso
Female genital
cutting
OR Summary 55

\section{Community Education Program Scaled-Up in Burkina Faso}

\begin{abstract}
A broad-based educational program developed in Senegal by Tostan and adapted in Burkina Faso increased awareness of human rights and women's health, and reduced support for female genital cutting (FGC). Public discussion of FGC leads to change in traditional social norms.
\end{abstract}

\section{Background}

The government of Burkina Faso is committed to the improvement of women's reproductive health. Within this context, the Population Council's FRONTIERS Program collaborated with two nongovernmental organizations (NGOs), Tostan in Senegal and Mwangaza Action in Burkina Faso, to replicate the Tostan community-based education program. Originally developed in Senegal (see ORS 54), this program provides modules in local languages on hygiene, problem solving, women's health, and human rights as a means of promoting community empowerment to facilitate social change.

The intervention, implemented from 2000-2003 in the provinces of Bazega and Zoundwéogo in Burkina Faso with funding from the GTZ Supra Regional Project for the Elimination of FGC, compared the performance of 23 participating villages with that of 23 control villages. Overall, 578 women and 448 men participated in the program.

To measure the program's impact on awareness, attitudes, and behavior regarding reproductive health and FGC, researchers conducted pre- and post-intervention surveys of women and men in the intervention and control areas, and qualitative interviews with key community members (including village chiefs and nurses). To measure the diffusion of knowledge, researchers also surveyed men and women who lived in the intervention area but did not participate in the study. They also assessed pre-and post-

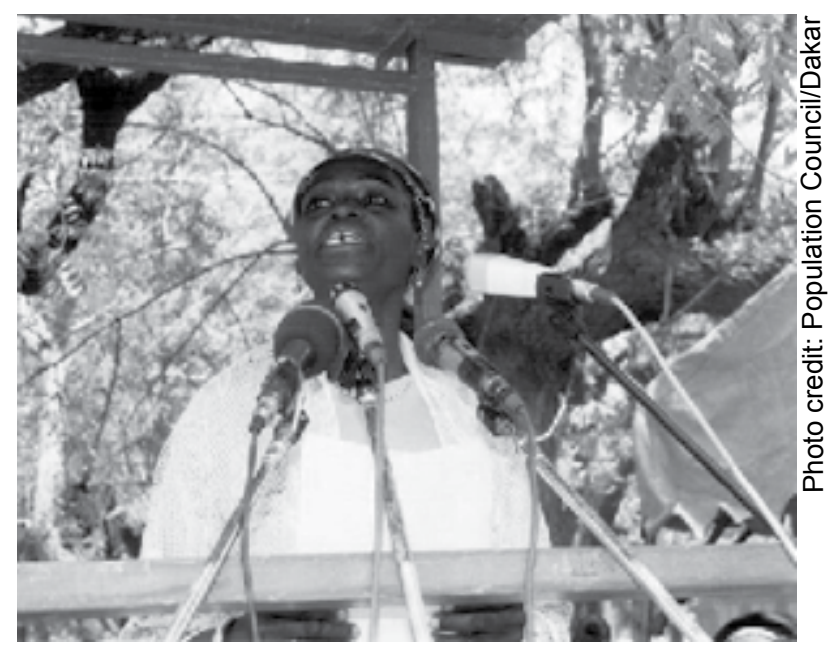

Woman calls out the names of all the communities taking part in the public declaration ceremony renouncing FGC.

intervention changes in the number of girls under 10 who had been cut.

\section{Findings}

- About two-thirds of the participants (63\% of the women and $60 \%$ of men) attended all four modules of the educational program. The main reasons for not taking part in the full program were travel and lack of time, illness and pregnancy. The women's health and hygiene modules had the highest attendance (over 70\%), while the human rights and problem-solving module had the lowest ( $25 \%$ and $18 \%$ ).

- Knowledge of the negative consequences of FGC, already strong at baseline, increased significantly among female ( $82 \%$ to $97 \%$ ) and male $(85 \%$ to $97 \%)$ participants. 
Participation in the intervention had a greater effect on views about FGC. In addition to classes, participants held skits about FGC in their villages and initiated discussions. Over 90 percent of female and male participants reported discussing FGC with others after the intervention. Most female participants $(96 \%)$ were in favor of the abandonment of FGC compared to 77 percent of nonparticipants. This contrasts with merely 60 percent of women in the control area and 66 percent of men. Almost 85 percent of female participants and 91 percent of male participants surveyed at endline said that they were ready to publicly discuss FGC.

Disapproval of FGC increased significantly among men and women in the intervention area, reaching 98 percent; however little change was seen in the control area (see Table). The proportion of female participants expressing regret at having their daughter cut significantly increased after the intervention (53\% to $81 \%$ ). There was no significant change among nonparticipants or among women in the control area.

- The proportion of girls aged 10 and under who had been cut decreased (from $6 \%$ at baseline to $3 \%$ among intervention participant families and $1 \%$ among nonparticipating families), but remained unchanged at 4 percent in the comparison group.

\section{- In 2003, representatives of 34 villages in the} intervention area participated in a public declaration denouncing FGC and early marriage, and affirming their intention to protect the health of women and children.
Attitudes of women and men towards FGC

\begin{tabular}{|c|c|c|c|c|c|}
\hline & \multicolumn{3}{|c|}{ Intervention group } & \multicolumn{2}{|c|}{ Comparison group } \\
\hline & \multirow[t]{2}{*}{ Baseline } & \multicolumn{2}{|c|}{ Endline } & \multirow[t]{2}{*}{ Baseline } & \multirow[t]{2}{*}{ Endline } \\
\hline & & Participant & $\begin{array}{c}\text { Non } \\
\text { participant }\end{array}$ & & \\
\hline WOMEN (n) & 6622 & 578 & 167 & 226 & 228 \\
\hline $\begin{array}{l}\text { Disapprove of } \\
\text { FGC }\end{array}$ & 89 & $98^{*}$ & 91 & 90 & 94 \\
\hline $\begin{array}{l}\text { FGC violates } \\
\text { women's rights }\end{array}$ & - & $99^{*}$ & 98 & 97 & 96 \\
\hline MEN (n) & 697 & 448 & 169 & 227 & 229 \\
\hline $\begin{array}{l}\text { Disapprove of } \\
\text { FGC }\end{array}$ & 90 & $98^{*}$ & $95^{*}$ & 93 & 89 \\
\hline $\begin{array}{l}\text { FGC violates } \\
\text { women's rights }\end{array}$ & - & $96^{*}$ & 72 & - & 73 \\
\hline
\end{tabular}

${ }^{*} p<0.05$
The majority of participants (66\% of women and $74 \%$ of men) took part in the ceremony, which was widely known in the intervention area and attended by over 5,000 people. A larger proportion of male nonparticipants attended the ceremony than women ( $53 \%$ versus $27 \%$ ).

\section{Policy Implications}

- The community-based education program can be successfully adapted and replicated in new settings, facilitating broad scale-up in diverse settings with high prevalence of FGC.

- There is considerable demand for both educational activities and public discussion of FGC and related health issues in the community, suggesting the acceptability of social change efforts on sensitive health topics.

Source: Diop, Nafissatou J. et al. 2004. "Experience from a community-based education program in Burkina Faso: The Tostan program," FRONTIERS Final Report. Washington, DC: Population Council. See also "Senegal: Community education program increases dialogue on FGC," FRONTIERS OR Summary no. 54. Washington, DC: Population Council, 2005. Available on our website at www.popcouncil.org/frontiers or by e-mail: frontiers@pcdc.org

This project was conducted with support from the U.S. AGENCY FOR INTERNATIONAL DEVELOPMENT under Cooperative Agreement Number HRN-A-00-98-00012-00. 